\title{
Using Mixed Methods to Assess the Coping and Self-regulation Skills of Undergraduate Social Work Students Impacted by COVID-19
}

\author{
Dawn Apgar $^{1}$ (1) . Thomas Cadmus ${ }^{1}$ \\ Accepted: 25 January 2021 / Published online: 11 February 2021 \\ (c) The Author(s), under exclusive licence to Springer Science+Business Media, LLC part of Springer Nature 2021
}

\begin{abstract}
Developing coping and self-care strategies has always been important for social work students as they prepare for work that can take a psychological, emotional, mental, and physical toll and adversely impact their health and well-being. The COVID-19 pandemic is unprecedented in its impact on social work education as it forced students to quickly transition to online learning and leave field sites abruptly to do remote activities. The degree to which and how social work students effectively coped with these changes has not been adequately studied, despite recognition that understanding how personal experiences and affective reactions influence professional judgment and behavior is a critical social work competency. To help fill this void, a mixed-methods study was conducted using video narratives and survey data to assess the coping and self-regulation skills of a cohort of undergraduate social work students. Findings indicate that these students experienced multiple stressors in all aspects of their biopsychosocial functioning due to COVID-19. Many coping skills learned for use with clients were demonstrated by students themselves. Self-sufficient, avoidant, and socially-supported coping mechanisms were frequently used and relied on by students. Use of self-distraction and active coping increased, while denial decreased within the first month after transitioning to remote learning. Implications of the findings for social work education, practice, and research are discussed.
\end{abstract}

Keywords Coping $\cdot$ Social work education $\cdot$ COVID-19 $\cdot$ Self-regulation

\section{Introduction}

The COVID-19 pandemic is having a profound effect on all aspects of society, including mental health. The pandemic has particularly and profoundly impacted students due to restrictions imposed by physical distancing within the education system. Leading experts in behavioral health have called for greater research to understand the extent of the psychological and social effects resulting from COVID-19, especially among children and young adults (Holmes et al. 2020). Although a rise in anxiety and stress are expected due to public policies imposed by physical distancing, little is known about the coping skills used to mitigate the negative impacts of these emotions during the pandemic. Directives to stay at home, which began in California in mid-March,

Dawn Apgar

dawn.apgar@shu.edu

1 Department of Sociology, Anthropology, Social Work, and Criminal Justice, Seton Hall University, 400 South Orange Avenue, South Orange, NJ 07079, USA quickly swept the nation. By April 20, 2020, about 316 million people in 42 states, three counties, 10 cities, the District of Columbia and Puerto Rico were urged to stay home as much as possible, in an act of solidarity that public health experts say was crucial to controlling the spread of COVID19 (Mervosh et al. 2020).

Physical distancing policies abruptly interrupted the lives of Americans, especially college students who have had to vacate campuses and move to entirely online and remote learning (Quintana 2020). On March 6, 2020, the University of Washington became the first major university to cancel in-person classes and exams. By the middle of March, colleges across the country had followed suit with more than 1100 colleges and universities in all 50 states cancelling in-person classes or shifting to online/remote instruction (Smalley 2020).

In social work, like other helping disciplines, significant education results from hands-on learning in field internships, which is deemed the signature pedagogy of the profession (CSWE 2015). To ensure student safety, the Council on Social Work Education (CSWE) both reduced the number 
of required field hours to $85 \%$ of its original standard and allowed remote field activities (https://www.cswe.org/ CSWE/media/AccredidationPDFs/COA-Field-ReductionUpdate-05-09-2020.pdf). This accommodation resulted in a significant departure from the typical educational experience of social work students.

Social workers are considered essential workers and often on the frontlines in crises (Alston et al. 2018). In this pandemic, the Council on Social Work Education (CSWE) called upon social workers "to adapt more quickly than ever before to meet the immediate needs" of others (http://www. socialworkblog.org/practice-and-professional-developmen t/2020/05/lets-call-it-what-it-is-telesocialwork/). However, as the world continues to grapple with the implications of COVID-19, the academic literature is void of data on the degree to which social work students, especially those are who entering the workforce in the midst of the pandemic, fared with regard to their own coping. Such research is seen as critical in order to "understand the psychological (e.g., coping), physiological (e.g., sleep and nutrition), and structural (e.g., work rotas and daily routines) factors that protect or adversely affect" future mental health professionals (Holmes et al. 2020, p. 3).

While social work students should learn about and use self-care strategies to manage typical educational demands and maintain their own well-being, the degree to which these self-care strategies are taught and resulted in coping skills present during remote learning due to COVID-19 is unknown. This study used a mixed-methods approach, through the analysis of video narratives and survey data collected from undergraduate social work students, to help better understand students' personal experiences and affective reactions to COVID-19.

\section{Literature Review}

\section{Relationships Between Stress, Coping, and Self-regulation}

Even before COVID-19, stress was on the rise, particularly among young adults (Burwell 2018). Evidence shows that stressful events are often the precursor to anxiety and depression (Schneiderman et al. 2005). However, stress itself is not harmful and can be beneficial. Stress, as a biological and physiological reaction, is meant to activate the fight-orflight response to aid in short-term survival (Matta 2012). In minimal doses, working under psychological stress, such as the time pressure of a deadline, can increase productivity (Baethge et al. 2018). Further, being exposed to stress can increase resiliency and make it easier to manage stress in the future (Seery et al. 2010). Short periods of stress, which are controlled, should be distinguished from chronic stress which is maladaptive and detrimental (Minois 2000; Rohleder 2019). Long-term stress can be harmful both physically and mentally; therefore, it is necessary for individuals to process their stress effectively to avoid negative outcomes, like depression and/or anxiety (Roming and Howard 2019).

The aim of coping is the reduction of the negative effects of stress (Heffer and Willoughby 2017). Coping skills are essential as they can dictate how people respond to stressful situations and how they work through and process difficult experiences (Wang et al. 2020). Stress varies widely from person-to-person as a result of cognitive appraisals, a concept developed by Lazarus and Folkman (1984). A cognitive appraisal is the personal and subjective interpretation of an event that dictates to what extent the situation is viewed as stressful and how a person responds or does not respond. Given that chronic stress is harmful, coping skills are essential for good health as they serve as an antidote to mitigate harm (Koperski et al. 2015).

Unlike stress and coping, self-regulation is less discussed, though it is a critical skill. Emotional self-regulation is the ability to manage troublesome thoughts, feelings, and emotions, and to respond appropriately (Reeck et al. 2016). As stress is unavoidable, self-regulation is essential for emotional growth, effective coping, and general life satisfaction (Boekaerts et al. 2000). Murray et al. (2015) describe self-regulation as "the foundation for lifelong functioning," resulting in better physical, mental, and emotional health, as well as academic and socio-economic success (p. 3). Stress and anxiety can impede self-regulation skills, so it is important to have useful, adaptive, and positive coping mechanisms to self-regulate negative emotions and feelings (Strait et al. 2020).

\section{Importance of Coping and Self-regulation for Social Work Students}

College students experience disproportionately high levels of stress and are at risk for stress-related mental and physical health disorders (Hirsch et al. 2019; Leppink et al. 2016). Stressors for college students include transitioning to new environments away from home, family, and friends; pressures from their academic workload; financial worries; and fears about their futures (Shi 2019). The combined effect of these factors during the same period make college students particularly vulnerable to the numerous deleterious mental and physical effects of stress, including depression, anxiety, weight gain, sleep disturbances, and substance use.

Teaching social work students about coping and selfcare is especially essential as they experience both the stress associated with college and the existence of secondary traumatic stress (STS) and vicarious trauma (VT) in their field work with clients (Owens-King 2019). CSWE requires social work students to demonstrate professional 
and ethical behavior which includes "understanding how their personal experiences and affective reactions influence their professional judgment and behavior" (CSWE 2015, p. 7). To achieve this competency, social workers must use reflection and self-regulation to manage personal feelings that can negatively interfere with professionalism that is central to social work practice. Learning how to cope with stress is also critical to avoiding professional impairment which interferes with competent practice according to the profession's ethical code (NASW 2018). Thus, educating students in social work programs about self-care should be of paramount importance as students, who are relatively inexperienced and newer to the workplace, are at a higher risk of compassion fatigue, which can occur when working with any client population (Martin et al. 2020). Not learning proper coping mechanisms in school can leave students and recent graduates susceptible to STS and VT, both of which can lead to burnout (Newell and Nelson-Gardell 2014; Wilson 2016).

Despite the importance of these topics for social work education, research indicates that voluntary activities aimed to bolster these skills are poorly attended and not seen as important to students studying social work (Taylor et al. 2020). While recognizing the usefulness of developing a self-care routine and learning coping mechanisms, and even having a desire to practice self-care, social work students struggle to engage in self-care for various reasons which include a lack of energy, too many responsibilities, and the fear of appearing weak or vulnerable (Diebold et al. 2018). Additionally, both social work students and practitioners often have difficulty putting themselves first and acknowledging that their needs deserve to be made a priority, viewing self-care as non-essential and something to be engaged in only when needed or when time permits. The prioritization of self-care is especially difficult for social workers who are struggling financially due to low wages and feel pressured to work harder to meet their daily needs (Miller et al. 2018).

\section{Stress and Coping of Helping Professionals in a COVID-19 World: Unique Challenges}

The adverse impacts of COVID-19 on students worldwide, especially those in the helping fields, are beginning to be researched, understood, and documented (Cao et al. 2020; Chen et al. 2020; Ullah and Amin 2020). According to a recent survey, the majority $(80 \%)$ of college students say that COVID-19 has negatively impacted their mental health (Active Minds 2020). Almost all college students (91\%) report that COVID-19 has caused them stress or anxiety, $81 \%$ state that it brought disappointment or sadness, and $80 \%$ have experienced loneliness or isolation. These emotions are occurring at particularly important times in students' lives, when they are often just learning to live and cope on their own.

Research has shown that psychopathologies may arise after exposure to a traumatic disaster, with post-traumatic stress disorder (PTSD) being the most common (Adams and Boscarino 2006; Galea et al. 2005; Neria et al. 2011). Drawing upon research done after the $9 / 11$ terrorist attacks, it is likely that the COVID-19 pandemic will lead to high rates of PTSD, depression, and substance misuse among first responders and others in the helping professions (DePierro et al. 2020). As in the wake of 9/11, confusion, fear, and concerns about the future are rampant during the COVID-19 pandemic. According to the Pew Research Center (2020), nearly 9 in 10 Americans say that COVID-19 has impacted their lives. In the same way researchers have written about a "post-9/11" world, the term "post-COVID" world is already being used by reputable organizations, such as the National Foundation for Infectious Diseases (NFID). Like 9/11, COVID-19 appears to both short- and long-term, economic, cultural, social, and psychological effects (Galea et al. 2020). However, nearly half of all college students state that they would not know where to go for mental health services (Active Minds 2020). This statistic is worrisome as some of these students, including those studying social work, may be called upon to assist with remedying the far-reaching impacts of COVID-19 after graduation.

To slow the spread of new infections, public health officials implemented "physical distancing" requirements (Feng et al. 2020) which is a trademark of the COVID-19 pandemic that differs from other natural disasters (Oosterhoff et al. 2020). Physical distancing aims to reduce the spread of COVID-19, but can cause isolation, loneliness, and mental health issues (Fegert et al. 2020). Further, physical distancing inhibits the ability for a community to come together during and after a crisis to collectively repair what is destroyed (Polizzi et al. 2020). It is estimated that physical distancing in the United States will likely last 18 months or until a vaccine is made available (Bline 2020). Thus, the prolonged nature of the COVID-19 crisis will likely impact stress levels, coping mechanisms, and self-regulation skills of all, including social workers, in ways that have not been examined.

This exploratory study aims to provide information on the coping skills and self-regulation of undergraduate social work students during COVID-19. Much of the work on coping and self-regulation within the professional literature focuses on stressors caused by occupational demands (Siebert 2006), and coping as a method to avoid burnout in a field with high turnover (Lloyd et al. 2010). This study provides a unique opportunity to understand the lived experiences of undergraduate students in their own words, through video and written narratives, which were made in the initial weeks of the COVID-19 pandemic. The degree to which 
and how social work students were able to effectively cope during the abrupt move to remote instruction is investigated in an effort to understand the unique stressors of social work students graduating during a public health crisis.

\section{Methods}

\section{Sample}

The sample consists of 19 senior undergraduate social work students enrolled in a capstone course at a northeastern university during Spring 2020, the semester just prior to their graduation. A capstone course bridges the transition from education to employment, with a focus on experiential learning activities aimed at promoting assessment, integration, scholarship, identity development, and application (Apgar 2019). Typically, students fulfill course requirements by attending off-campus activities such as conferences, meetings of professional associations, and in-person continuing education events. Seventeen students were scheduled to complete degree requirements by May 2020, one was taking summer courses finishing by August 2020, and one was graduating in December 2020, needing an extra semester to fulfil coursework for a second major.

Aggregate data, collected at the beginning of the semester on these students, indicated that $88 \%$ were female $(12 \%$ male), $53 \%$ were under age 22 (17\% were $22-24,12 \%$ were $25-29,6 \%$ were $30-34$, and $12 \%$ were 45 and older), and $44 \%$ identified as White (31\% as Hispanic/Latinx, $13 \%$ as Black/African American, and 12\% as multiracial). Eightyone percent indicated a desire to work in the United States after graduation with $19 \%$ wanting to work internationally. Only $31 \%$ indicated that they would be graduating without any personal student loan debt.

While small, this study sample closely mirrors the composition of new BSW graduates nationally regarding gender and age but appeared to be more racially/ethnically diverse (George Washington University, 2018). This difference is not surprising as the students in the sample were attending an urban school, located just 14 miles from a major city in the Northeast.

Students received notification on March 10th, the day of the first recorded death due to COVID-19 in the State, that in-person classes were suspended for 3 days after an emergency declaration by the Governor the previous day. On March 12th, students were notified that this suspension of classes would be extended until March 16th, at which time all courses would be taught remotely until April 13th. On March 21st, as the number of COVID-19 cases in the State surpassed 1000, the Governor announced a statewide "stayat-home order," requiring that all non-essential businesses be closed indefinitely. On March 27th, students were notified that remote learning would continue for the remainder of the semester. By the end of the semester, there were a reported 118,652 total cases of COVID-19 and 7228 associated deaths (Arco 2020), with the State still in the initial phase of a three-part reopening plan which required face coverings worn at all times, public transportation at 50\% capacity, and essential businesses operating on a limited basis.

Within the undergraduate social work program, coping skills were regularly taught in six courses within the curriculum. Specific readings were assigned, and didactic discussions occurred on self-care, burnout, compassion fatigue, STS, and VT. Additionally, students engaged in experiential learning exercises on coping techniques (journaling, cognitive reframing, mindfulness, biofeedback, etc.) that could be used with clients. For example, a course instructor presented an activity related to externalization when introducing narrative theory, inviting students to try the activity themselves while promoting it as a viable intervention with clients.

\section{Data Collection}

\section{Qualitative Data}

Video Narratives Students were asked to create short (3 min) videos weekly about their feelings and experiences related to COVID-19 generally and the impacts of physical distancing. The use of video narratives was chosen as they have been shown to be effective in gaining insights into subjects' thoughts and emotions (Kwasnicka et al. 2015). Students posted them on a secured website that could only be accessed by fellow classmates. A total of 66 student videos were created about the pandemic with students responding to various prompts to help them focus their postings.

Twenty-nine of the 66 videos were selected for use in this study as they documented student responses to two prompts that directly related to the study's purpose. The first prompt asked students to assess their functioning using a biopsychosocial perspective and the other asked about coping mechanisms utilized to address stressors. The total length of all 29 videos, which were recorded on April 6th $(\mathrm{n}=13)$ and April 23rd $(n=16)$, was $1 \mathrm{~h}, 31 \mathrm{~min}$, and $25 \mathrm{~s}$. The other 37 student videos were not used in this study as students were not prompted to speak about their own stress or coping, but rather other facets of the pandemic (such as the extent to which COVID-19 impacted special populations or ethical issues related to medical treatment).

When analyzing the 29 videos, four tasks associated with content analysis-decontextualization, recontextualization, categorization, and compilation-were used to reduce the impact of researcher bias and enhance the reliability and validity of identified themes (Bengtsson 2016). Using an inductive approach, two independent raters-a social work faculty member and student—identified 'meaning units' or 
key theses while watching all 29 videos twice and taking notes on latent and manifest content. These meaning units were groups into themes, which were collapsed or expanded when appropriate, to ensure that all stressors and coping mechanisms were represented (decontextualization). A third viewing of all videos was done to record direct quotes from students for each theme (recontextualization). There were discussions between raters regarding two video segments to identify whether additional themes were needed, or they were represented by existing ones. It was agreed that these narratives fit within the original themes but expanded their meaning (categorization). Finally, the compilation of video narratives was compared with the written narratives to identify consistencies and differences.

Only verbalizations were analyzed; body language was not considered. The decision to not code body language was made after an extensive review of the literature on nonverbal communication. Much of this literature stressed the importance of body language, as opposed to facial expressions, in meta-communication (de Gelder 2009). The videos were restricted to the face only with students recording them from university-issued laptop computers. It was not possible to view their posture, arms, etc., making body language assessments impossible. A decision was also made not to include facial expressions as students often recorded the videos outside or in their cars as these were the only private locations available since they were at home with family members who were also quarantining. Students squinted and made facial expressions that appeared to often be related to the conditions under which they recorded. Thus, this data did appear consistently relevant or to add to the research aims.

Written Narratives Students were asked to briefly summarize their coping in their own words, responding to the following question, "What do you think is important to know about your coping with the impacts of COVID-19?" This question was asked twice-once a week after classes were suspended and moved to remote learning and the second time at the end of the semester (April 30th), after students had been attending classes remotely for 6 weeks. Information provided in these written accounts was analyzed using the same iterative process as the video narratives. However, a deductive approach was taken using the themes already identified through analysis of the video narratives. Interestingly, the same original themes were found in the written narratives, as confirmed by the two independent raters.

\section{Quantitative Data}

Brief COPE To assess coping, a brief version (28 items) of the Coping Orientation to Problems Experienced (COPE) survey was used (Carver 1997). This abbreviated inventory of the complete 60-item COPE Inventory (Carver et al.
1989) reliably assessed the frequency with which different coping strategies were used, rated on a scale from 1, ("I haven't been doing this at all") to 4, ("I've been doing this a lot"). The brief COPE has been used extensively to assess coping, and found to be a reliable and valid measure with college students overall (Cramer et al. 2020; Flynn et al. 2020), including those in allied professions such as nursing (Ab Latif and Mat Nor 2016) and pharmacy (Garber 2017).

Carver (1997) designed the brief COPE to assess 14 distinct domains, warning against combining them into an overall measure unless indicated by analysis of individual data using reliability testing and/or factor analyses. Confirmatory testing of the factor structures used by Cummings et al. (2020) with protective service workers indicated that the three-factor model of self-sufficient (5 items), socially supported (3 items), and avoidant (6 items) coping was not appropriate for use with data in this study. However, these categories provide conceptual classifications which are useful in understanding study findings. Self-sufficient coping consists of items from the active coping, positive reframing, planning, humor and acceptance scales. Socially supported coping consists of items from the use of emotional support, use of instrumental support and religion scales. Lastly, avoidant coping consists of items from the self-distraction, denial, substance use, behavioral disengagement, venting and self-blame scales.

Scores in each of the 14 individual domains could range from 2 to 8 as each contained 2 items. Lower scores indicate engaging in the activity with less frequency and higher scores the contrary. The brief COPE was administered twice. The first brief COPE was completed a week after classes were suspended and students moved to remote learning. The second administration was at the end of the semester (April 30th), after students had been attending classes remotely for 6 weeks. On both occasions, using Qualtrics, the brief COPE was administered in conjunction with solicitation for the written narratives.

\section{Informed Consent and Institutional Review Board Approval}

The study was approved by the Institutional Review Board (ID\# 2020-076) with separate written consents by students for use of their survey data and videos. While data were collected during the semester as part of a capstone course, students had the opportunity not to participate in the study. They were asked after the semester had ended and grades posted if they would like to participate and submit information for this research study. Their participation was in no way linked to their grade in the capstone course and as seniors, their formal relationship with the social work program and its faculty had officially ended. Videos were not anonymous as students identified their names and school affiliation at 
the start of each recording. After reviewing detailed consent forms that specified that videos would be used for research and presentations on the findings, all students in the capstone course decided to participate. All consent forms had to comply with the Health Insurance Portability and Accountability Act (HIPAA 1996), given that the identities of students were recorded and known. Many students commented that they saw participation as their legacy by which they could contribute to the knowledge base of the profession, perhaps helping others in similar situations in the future.

\section{Limitations}

The study is not without limitations that threaten its external and internal validity. The sample is a small undergraduate student cohort at a single university which was conveniently selected, limiting the potential generalizability of results. Data indicates that this sample may be more racially/ethnically diverse than BSW students nationally which could result in differences in coping. In addition, the magnitude of the COVID-19 impacts may have varied between students. The actual magnitude of the stressors was not assessed. The video and written self-reports of students comprised perceived stressors only, with coping described over a short time period. The long-term impacts of COVID-19 on students' lives and self-care abilities are unknown and may be markedly different than those found in this exploratory study. Lastly, students may be been reluctant to disclose some coping behaviors, such as substance use, due to a social desirability bias. These behaviors may be underreported, impacting the internal validity of the study to detect both usage and changes in these coping strategies.

\section{Results}

\section{Qualitative: Video and Written Narratives}

\section{Stressors Due to COVID-19}

Students reported that they experienced stressors in every aspect of their lives due to COVID-19. When discussing the biological impacts of COVID-19, students overwhelmingly agreed that intangible losses, specifically regarding their daily routines, had been particularly challenging. Five students reported sleeping more, others less. Students universally stated that routine disruptions resulted from no longer having strict schedules to adhere to and not needing to wake up to attend school, work, or their internships. Likewise, students' eating habits had been erratic. Two students reported not feeling safe enough to go to the grocery store, leaving them with few options. On the topic of food insecurity, one of two students remarked, "I eat pretty healthy and fresh, and right now I am not doing so. I'm trying to do more boxed pasta and rice since I am trying not to go to the grocery store."

Students also said that the pandemic has forced them to change how they viewed exercising. One student remarked that exercising at the gym was a way to destress from his responsibilities; now, since gyms were closed, he had to rethink how he stayed active and coped. He stated that he did not feel comfortable enough to exercise outside and that is was not worth the risk to his family's well-being.

One student discussed her experience of having Type 1 Diabetes and, while it does not place her at a higher risk of contracting the virus, it could complicate the recovery process. Due to her pre-existing condition, she needed to observe strict physical distancing guideline, perhaps more so than her peers.

Lastly, two students reported having the virus itself. Both discussed the challenges of being ill in addition to their personal and professional responsibilities as students, employees, and family members. One student, who is also a mother, tested positive for COVID-19 during the semester and remarked how meeting academic and work requirements were more difficult while she was ill. More importantly, she stated that quarantining away from her children was impossible as they are young and need her physical assistance.

Psychologically, all students stated that they experienced high levels of stress and anxiety, particularly regarding how the pandemic is being handled by federal, state, and local leaders. Students reported worrying about the health of their parents, some who are immunocompromised. A student worried about the health of his father.

My father, who is older, has a suppressed immune system due to his arthritis. He is a mail carrier, making him more exposed to the virus. Although he has protective gear that his job has provided, I still worry about his health and the health of my mother and me.

The economic situation also caused financial stress for students, three of whom lost jobs and left some looking for work. One student said the loss of income made him feel like he was in "survival mode." Some students were essential workers and still working, having to manage the stress associated with the possibility of being asymptomatic carriers and bringing the virus home to their families or roommates. A student discussed psychological challenges, including self-blame and guilt, saying:

I've been bored out of my absolute mind. I'm finding myself very irritable and easily frustrated, specifically in the relationships close to me and I somewhat attribute that to being isolated and not being able to see them and having that physical connection and contact. I find myself absolutely filled with worry about 
the pandemic around the globe; I can't stop thinking about it.

One student reported that her mother passed away at the beginning of the quarantine and that COVID-19 negatively affected her grieving process. She had been unable to see her family and needed to rely solely on technology for communication with others to assist with support and healing.

A student who was ill herself with COVID-19 also had a household member become infected. She stated that the situation affected her psychologically, including making her doubt her future career as a social worker, "Psychologically, I felt pressure, devastated, depressed, and I felt like I wouldn't be able to complete my career as a social worker."

Physical or social distancing posed the greatest challenge for students. All students stated that, as classes shift online, they felt disconnected from their peers as many kept themselves muted and turned off their cameras during remote instruction. For some, this lack of connection lowered their motivation in their classes and schoolwork as they felt in-person dialogue which was beneficial to learning was something that lacked with virtual learning. Students indicated that physical distancing resulted in loneliness. While most students were utilizing virtual techniques (like video chatting, phone calls, text messaging, etc.) to connect with others, many commented that these methods were less preferred. Six students lived with roommates or peers and were quarantining away from their families, noting this arrangement as difficult. One student stated that they lived with only one of their parents, unable to see the other aside from short visits.

\section{Coping Mechanisms and Self-regulation}

All students in the study indicated that they had to implement new coping mechanisms to deal with the stress and anxiety caused by COVID-19. Several themes emerged, including utilizing social media, accepting the situation, exercising, using self-distraction or mindfulness, relying on faith and spirituality, and being altruistic. Since the videos related to coping were recorded 4 weeks after the move to remote learning, students seemed to have accepted the reality of the pandemic and its impact on society. Nearly every student recognized the need to work on building daily routine for sleeping, eating, and doing schoolwork as that had been one of the biggest shifts in their lives. Exercise, too, was an important coping mechanism cited. Seven students went for walks, jogs, or exercised in/around their house. Technology and social media appeared to be a widely used tool for coping. Three of these students used apps for their home workouts, while another five used them for breathing exercises and guided meditations. Others watched videos and used the time to learn new things. Perhaps the most widely used function of technology was to stay in touch with friends and family. Students video chatted, spoke on the phone, and texted family and friends. Sixteen students also said that they have utilized this time to reach out to friends they may not have spoken to in a while.

Four students used their faith for hope and peace during this tumultuous time. Faith was noted by students to provide balance, hope, and peace during a time replete with stress and anxiety. Similarly, students noted that meditating, whether guided or unguided, helps them to calm and ease their worries while promoting peace.

As of today, I am coping with COVID-19 by remaining active and strong in my faith and trust in God. I have found that this has been very helpful for me to keep me motivated, to keep me strong, to encourage myself, and also provided me the strength to encourage other people during this difficult time.

Students also noted utilizing coping mechanisms geared toward self-distraction by engaging in hobbies they may not have the time for normally, including watching television shows or movies, cleaning and organizing, playing video games, cooking, and/or playing instruments.

Students also engaged in altruistic acts, such as helping others, encouraging others, and supporting them. One student allowed a friend, who was struggling to cope mentally with the crisis, to stay with her and her boyfriend so he was not alone. She stated:

We have a friend who has been quarantining as long as we have. He's been totally alone and he hasn't been feeling good mental health wise, so we're actually bringing him to the house tonight so we can all quarantine together. Having someone stay with us because they're not feeling good seems like the right thing to do right now.

Another student echoed the desire to be altruistic and commented that it reaffirmed her decision to become a social worker. Interestingly, this statement was given by the student who had doubted her career choice as a social worker during her experience with COVID-19. However, she, along with three other students, spoke with renewed vigor about their commitment to the social work profession and were eager to either enter the workforce or continue to graduate school.

There were two noteworthy self-regulation tactics, positive reframing and self-talk, which were repeatedly mentioned by many students due to their use for effective coping. When positive reframing, students challenged their cognitive distortions and reframed them in ways that were adaptive. For example, one student remarked that she challenged negative cognitive schemas that made her feel "lazy" and "unproductive" by reframing them more positively. She would remind herself that she was taking a much-needed 
break from the busyness she faced daily for many years. A second student noted that during particularly hard moments, she would use self-talk to remind herself that this pandemic would eventually come to an end and that she could then begin working as a social worker on helping others affected by this virus.

Students connected the strategies they used for coping and self-regulation to their undergraduate social work education. For example, one student who had been practicing meditation and mindfulness as a coping tool stated, "This (mindfulness) is something I learned ... in one of (my) classes and I've been using it ever since....it helps me reconnect with myself and eases my stress and worry." Another student directly linked the strategies she has been using to the cognitive-behavioral therapy techniques learned in the classroom. For example, the student said she has been challenging her negative and unhelpful thoughts and using reframing to counteract negative cognitive distortions and schemas.

\section{Quantitative: Brief COPE}

A review of the initial brief COPE scores of students (in rank order) revealed that substance use was the least frequently using coping mechanism while acceptance was the most (Table 1). Self-blame was also done not at all or very little by these students. Scores for self-distraction, use of emotional support, venting, and acceptance exceeded or approached 6 meaning these activities were done at least moderately.

Scores obtained 6 weeks later, after students had been home for 6 weeks and were only participating in remote learning, indicated low levels of denial, behavioral disengagement, and substance use (in rank order). Use of emotional support, active coping, positive reframing, planning, self-distraction, and acceptance all had scores above six, indicating their use at least moderately.

Analyses of the changes over time indicate three significant results with denial going down and active coping and self-distraction engaged in more frequently.

\section{Discussion}

Undergraduate social work students experienced losses due to COVID-19 in all aspects of their biopsychosocial functioning, challenging their ability to cope. These stressors mirrored those experienced by Americans in general, with similar struggles reported by students nationally who moved to completely online or remote learning. Students stated that changes in their daily routines resulted in poorer eating habits and reductions in exercise, with fears about contracting or managing the virus being concerns for those
Table 1 Undergraduate social work student scores on the brief COPE

\begin{tabular}{lllll}
\hline Subdomain & \multicolumn{4}{l}{ Mean score (in T1 rank order) } \\
\cline { 2 - 5 } & Time 1 & Time 2 & Difference & Significance* \\
\hline Substance use & 3.32 & 3.42 & .10 & $\mathrm{NS}$ \\
Self-blame & 3.58 & 4.11 & .53 & $\mathrm{NS}$ \\
Behavioral disengage- & 4.26 & 3.37 & -.89 & $\mathrm{NS}$ \\
$\quad$ ment & & & & \\
Religion & 4.58 & 5.11 & .53 & $\mathrm{NS}$ \\
Humor & 4.63 & 4.05 & -.58 & $\mathrm{NS}$ \\
Denial & 4.84 & 3.05 & -1.79 & $\mathrm{p}<.004$ \\
Active coping & 5.21 & 6.31 & 1.10 & $\mathrm{p}<.039$ \\
Positive reframing & 5.37 & 6.42 & 1.05 & $\mathrm{NS}$ \\
Use of instrumental & 5.53 & 5.53 & .00 & $\mathrm{NS}$ \\
$\quad$ support & & & & \\
Planning & 5.89 & 6.47 & .58 & $\mathrm{NS}$ \\
Self-distraction & 5.95 & 6.84 & .89 & $\mathrm{p}<.030$ \\
Use of emotional sup- & 5.95 & 6.21 & .26 & $\mathrm{NS}$ \\
$\quad$ port & & & & \\
Venting & 6.00 & 5.11 & -.89 & $\mathrm{NS}$ \\
Acceptance & 6.26 & 6.84 & .58 & $\mathrm{NS}$ \\
\hline
\end{tabular}

Each subdomain consists of two items which were rated on a fourpoint Likert scale of 1 ("I haven't been doing this at all") to 4 ("I've been doing this a lot")

*NS not significant

with preexisting conditions or parents who had childcare responsibilities, respectively.

The psychological impacts of self-quarantining appeared to be the most difficult, with worry about the future cited as a paramount concern. The loss of connection with others was perceived as a significant problem, especially for those who were grieving. The lack of face-to-face contact resulted in many turning to social media to avoid feeling isolated and lonely. Students who longed for connection reported that remote learning did not meet this need as many students kept their cameras off or were muted during class sessions. Avoidance and procrastination were cited as problems attributed to the loss of structure of attending in-person classes and field activities.

The need to physically distance from family members was an added strain for students who were living in on-campus or local apartments as they could not return home for fear of infecting others. Harming parents who were elderly or had existing health issues was a worry, especially because students recognized that they could be asymptomatic carriers of the virus.

Both qualitative and quantitative data revealed various coping strategies used by undergraduate social work students. Based on qualitative data obtained in their video narratives, students reported utilizing the knowledge gleaned from their social work education to, first and foremost, understand and recognize the challenges COVID-19 posed 
to them and, secondly, to address the need for healthy and positive coping skills to address these challenges. Many of the coping strategies that students mentioned using were those which they had been taught in the undergraduate social work program. While not prompted to speak about how they applied classroom material to their own coping strategies, students mentioned exercise, breathing, guided meditations, and other relaxation techniques as beneficial approaches, all of which had been taught in practice courses. Faith was also mentioned as important to coping, with the role of spiritual well-being as an important part of biopsychosocial functioning stressed repeatedly throughout the social work curriculum. Given the ability of students in this study to readily apply self-care strategies learned in the classroom to enhance their own mental health, this study supports education about coping skills within the formal undergraduate social work educational curricula.

Quantitative data obtained from social work students supported their self-reports about coping. Using the coping schema developed by Cummings et al. (2020), students in the study often engaged in all three types of copingself-sufficient, avoidant, and socially supported. Acceptance (self-sufficient) was the most frequently used strategy, followed by venting (avoidant), use of emotional support (socially supported), and self-distraction (avoidant). However, only one of these-self-distraction-increased over time. Students reported that they used time to try new hobbies or reach out to friends that they had not contacted in a while. Cooking, cleaning, organizing, playing video games, and/or practicing musical instruments were all activities used to distract from media reports, with the reliance on these activities growing.

Quantitative data also revealed that social work students were less in denial (avoidant) and that their active coping (self-sufficient) increased significantly over time. These marked changes, coupled with an increase in self-distraction (avoidant), indicates that social work students were able to enhance their adaptive coping, at least in the initial weeks during the self-quarantine even with the switch to remote learning. The use of emotional support (socially supported) was used initially and remained steady with students often citing the use of social media to connect with family and friends. Generally, students felt the need to connect with one another and their friends/family, with use of emotional support rated as a frequently used coping strategy during the 6-week study period. One student cited the importance of knowing that "I am not alone in this journey."

Maladaptive avoidant strategies, such as substance use, self-blame, and behavioral disengagement, were rarely used initially and did not increase during the study period. Venting (avoidant) was frequently cited as a copying strategy initially, with decreases over time, though not significantly so. Talking about emotions and feelings is seen as important for both practitioners and clients and reinforced within social work courses. The affective domains of learning are stressed in competency development by CSWE. Thus, students may have seen venting as a method to express their reactions, including fears, frustration, and anger after abruptly receiving news about remote learning, which continued until the end of the semester.

\section{Implications}

Findings have important implications for social work education, practice, and research. Loss of connection was a significant stressor for students who had to quickly transition to remote learning and field work. While students used technology to informally reach out to family and friends, they relied on university policies to drive their remote learning experience. Clearly, social work educational programs need to develop and utilize methods by which students can support one another and learn how their clients remotely, regardless of the need for physical distancing due to COVID-19. Technology provides unique opportunities to do so. Video conferencing, group text messaging, and other means of electronic communication need to be used and/or enhanced within social work education, not just during remote learning. Students turned to social media to stay connected with family and friends but felt disconnected from their peers as many kept themselves muted and turned off their cameras during remote instruction. Social work educational programs may want to examine their existing policies with regard to technology use, including for remote teaching, to help students learn about and model supportive interactions with one another so that they can be used with clients via telehealth in the future.

Students in this study experienced stressors which were not anticipated or encountered in their daily lives. These situations reflect the lives of social work clients who find themselves addressing unanticipated problems. While the need for physical distancing due to COVID-19 will disappear over time, it provides social work students with the opportunity to perhaps better understand unanticipated crises encountered by others. This experience provides social work educators with the chance to use parallel processes to help students gain better clinical insights into the lives of current and future clients who may seek their help due to changes in their own life circumstances. Rarely does an entire cohort of students have the same collective experience which can be used to enhance clinical understanding and skills. COVID-19 provides a unique opportunity for students to learn about stress, coping, and self-regulation jointly firsthand. Educators should take advantage of this "teachable moment" in history as students themselves experience the effects of COVID-19 on all aspects of functioning and 
see the importance of environmental influences on individual functioning directly.

Self-care is recognized as critical for social workers but is rarely studied in those entering the field, especially during a time of national crisis. The long-term impact of COVID-19 on the career choices and burnout of social work practitioners deserves attention. Some students mentioned a renewed commitment to the profession and were excited about entering the workforce now. However, the extent to which their coping skills and optimism persist over time has not yet been studied.

Social workers have always promoted hope and seen opportunities in times of adversity. COVID-19 provides a valuable context in which to enhance understanding about stress, coping, and self-regulation of social workers who will certainly continue to be challenged by life's uncertainties for themselves and those they serve. COVID-19 provides the opportunity for social work students to practice what they have learned about the importance of self-care to avoid VT and STS, leading to burnout. Findings indicate that some coping skills were used by more prevalently by social work students in the initial weeks of self-quarantining and remote learning. Further investigation about how those regarded as adaptive, but not readily used, such as humor, can be promoted in professional practice should be undertaken.

This study was done "in vivo" during the initial weeks of the COVID-19 pandemic, allowing a unique opportunity to gather data on the stressors, coping, and self-regulation of social work students as they were experienced and used. It also utilized video narratives as a method to collect qualitative data from students during a time of physical distancing and isolation due to remote learning. These unique aspects of this exploratory study should be replicated. There is a need to confirm the current findings with larger samples at other universities, as well as determine the impact of demographic variables on coping strategies. Such inquiry was not possible in this research given the small sample size.

Most studies on stress, coping, and self-regulation, including those in the social work literature, utilize cross-sectional data, while this research demonstrated that changes in some coping strategies by social work students occurred significantly over a short period of time. There is a need for more longitudinal data when studying these constructs, especially as it relates to COVID-19. Changes in infection/death rates, and corresponding public policies aimed at curving transmission, will likely result in varying levels of stress, as well as adaptations in coping and self-regulation in the future.

\section{References}

Ab Latif, R., \& Mat Nor, M. (2016). Stressors and coping strategies during clinical practices among diploma nursing students.
Education in Medicine Journal, 8(3), 21-33. https://doi. org/10.5959/eimj.v8i3.422.

Adams, R., \& Boscarino, J. (2006). Predictors of PTSD and delayed PTSD after disaster: The impact of exposure and psychosocial resources. The Journal of Nervous and Mental Disease, 194(7), 485-493. https://doi.org/10.1097/01.nmd.0000228503 .95503.e9.

Active Minds. (2020). The impact of COVID-19 on student mental health. https://www.activeminds.org/studentsurvey/

Alston, M., Hargreaves, D., \& Hazeleger, T. (2018). Postdisaster social work: Reflections on the nature of place and loss. Australian Social Work, 71(4), 405-416. https://doi.org/10.1080/03124 07X.2017.1409776.

Apgar, D. (2019). Conceptualization of capstone experiences: Examining their role in social work education. Social Work Education, 38(2), 143-158. https://doi.org/10.1080/02615479.2018.1512963.

Arco, M. (2020). NJ coronavirus death toll surges to 7,228 with 118,652 total cases. Officials announce 460 new deaths, the highest single day increase. nj.com. https://www.nj.com/coronaviru s/2020/04/nj-coronavirus-death-toll-surges-to-7228-with-11865 2-total-cases-more-than-450-new-deaths-announced-in-highestsingle-day-increase.html.

Baethge, A., Vahle-Hinz, T., Schulte-Braucks, J., \& van Dick, R. (2018). A matter of time? Challenging and hindering effects of time pressure on work engagement. Work \& Stress, 32(3), 228247. https://doi.org/10.1080/02678373.2017.1415998.

Bengtsson, M. (2016). How to plan and perform a qualitative study using content analysis. NursingPlus Open, 2, 8-14. https://doi. org/10.1016/j.npls.2016.01.001.

Bline, L. (2020). March Modeling study suggests 18 months of COVID19 social distancing. MLO: Medical Laboratory Observer. https ://www.mlo-online.com/disease/infectious-disease/article/21130 554/modeling-study-suggests-18-months-of-covid19-social-dista ncing.

Boekaerts, M., Pintrich, P., \& Zeider, M. (2000). Handbook of selfregulation. New York: Academic Press.

Burwell, S. (2018). Generation stress: The mental health crisis on campus. Foreign Affairs, 97(6), 150-157.

Cao, W., Fang, Z., Hou, G., Han, M., Xu, X., Dong, J., \& Zhenga, J. (2020). The psychological impact of the COVID-19 epidemic on college students in China. Psychiatry Research, 287, 1-5. https:// doi.org/10.1016/j.psychres.2020.112934.

Carver, C. (1997). You want to measure coping but your protocol's too long: Consider the brief COPE. International Journal of Behavioral Medicine, 4(1), 92-100. https://doi.org/10.1207/s15327558i jbm0401_6.

Carver, C., Scheier, M., \& Weintraub, J. (1989). Assessing coping strategies: A theoretically based approach. Journal of Personality and Social Psychology, 56(2), 267-283. https://doi. org/10.1037/0022-3514.56.2.267.

Chen, Y., Zhou, H., Zhou, Y., \& Zhoua, F. (2020). Prevalence of selfreported depression and anxiety among pediatric medical staff members during the COVID-19 outbreak in Guiyang, China. Psychiatry Research, 288, 1-3. https://doi.org/10.1016/j.psych res.2020.113005.

Council on Social Work Education (CSWE). (2015). Educational policy and accreditation standards. Alexandria, VA: Author.

Cramer, R., Braitman, A., Bryson, C., Long, M., \& La Guardia, A. (2020). The brief COPE: Factor structure and associations with self- and other-directed aggression among emerging adults. Evaluation \& the Health Professions, 43(2), 120-130. https:// doi.org/10.1177/0163278719873698.

Cummings, C., Singer, J., Moody, S., \& Benuto, L. (2020). Coping and work-related stress reactions in protective services workers. British Journal of Social Work, 50(1), 62-80. https://doi.org/10.1093/ bjsw/bcz082. 
de Gelder, B. (2009). Why bodies? Twelve reasons for including bodily expressions in affective neuroscience. Philosophical transactions of the Royal Society B, Biological Sciences., 364, 3475-3484. https://doi.org/10.1098/rstb.2009.0190.

DePierro, J., Lowe, S., \& Katz, C. (2020). Lessons learned from 9/11: Mental health perspectives on the COVID-19 pandemic. Psychiatry Research, 288, 1-3. https://doi.org/10.1016/j.psych res.2020.113024.

Diebold, J., Kim, W., \& Elze, D. (2018). Perceptions of self-care among MSW students: Implications for social work education. Journal of Social Work Education, 54(4), 657-667. https://doi. org/10.1080/10437797.2018.1486255.

Fegert, J., Vitiello, B., Plener, P., \& Clemens, V. (2020). Challenges and burden of the Coronavirus 2019 (COVID-19) pandemic for child and adolescent mental health: A narrative review to highlight clinical and research needs in the acute phase and the long return to normality. Child and Adolescent Psychiatry and Mental Health, 14(1), 1-11. https://doi.org/10.1186/s13034-020-00329-3.

Feng, Z., Glasser, J., \& Hill, A. (2020). On the benefits of flattening the curve: A perspective. Mathematical Biosciences, 326, 1-3. https ://doi.org/10.1016/j.mbs.2020.108389.

Flynn, E., Thériault, É., \& Williams, S. (2020). The use of smartphones to cope with stress in university students: Helpful or harmful. Journal of Technology in Behavioral Science, 5, 171-177. https ://doi.org/10.1007/s41347-019-00125-7.

Galea, S., Merchant, R., \& Lurie, N. (2020). The mental health consequences of COVID-19 and physical distancing: The need for prevention and early intervention. JAMA Internal Medicine, 180(6), 817-818. https://doi.org/10.1001/jamainternmed.2020.1562.

Galea, S., Nandi, A., \& Vlahov, D. (2005). The epidemiology of posttraumatic stress disorder after disasters. Epidemiologic Reviews, 27(1), 78-91. https://doi.org/10.1093/epirev/mxi003.

Garber, M. (2017). Exercise as a stress coping mechanism in a pharmacy student population. American Journal of Pharmaceutical Education, 81(3), 1-6. https://doi.org/10.5688/ajpe81350.

George Washington University, Health Workforce Institute. (2018). Nationwide survey of 2017 social work graduates: The national social work workforce study. https://cswe.org/Centers-Initiative s/Initiatives/National-Workforce-Initiative/Survey-of-2017-SWGrads-Report-FINAL.aspx.

Health Insurance Portability and Accountability Act (HIPAA). (1996). Pub. L. No. 104-191.

Heffer, T., \& Willoughby, T. (2017). A count of coping strategies: A longitudinal study investigating an alternative method to understanding coping and adjustment. PLOS ONE, 12(10), 1-16. https ://doi.org/10.1371/journal.pone.0186057.

Hirsch, J., Rabon, J., Reynolds, E., Barton, A., \& Chang, E. (2019). Perceived stress and suicidal behaviors in college students: Conditional indirect effects of depressive symptoms and mental health stigma. Stigma and Health, 4(1), 98-106. https://doi.org/10.1037/ sah0000125.

Holmes, E., O'Connor, R., Perry, V., Tracey, I., Wessely, S., Arseneault, L., et al. (2020). Multidisciplinary research priorities for the COVID-19 pandemic: A call for action for mental health science. Lancet Psychiatry. https://doi.org/10.1016/S2215 -0366(20)30168-1.

Koperski, H., Tucker, A., Lung, D., \& Gass, M. (2015). The impact of community based adventure therapy on stress and coping skills in adults. Practitioner Scholar: Journal of Counseling \& Professional Psychology, 4(1), 1-16.

Kwasnicka, D., Dombrowski, S., White, M., \& Sniehotta, F. (2015). Data-prompted interviews: Using individual ecological data to stimulate narratives and explore meanings. Health Psychology, 34(12), 1191-1194. https://doi.org/10.1037/hea0000234.

Lazarus, R., \& Folkman, S. (1984). Stress, appraisal, and coping. New York: Springer Publishing Company.
Leppink, E., Odlaug, B., Lust, K., Christenson, G., \& Grant, J. (2016). The young and the stressed: Stress, impulse control, and health in college students. The Journal of Nervous and Mental Disease, 204(12), 931-938. https://doi.org/10.1097/NMD.0000000000 000586.

Lloyd, C., King, R., \& Chenoweth, L. (2010). Social work, stress and burnout: A review. Journal of Mental Health, 11(3), 255-265. https://doi.org/10.1080/09638230020023642.

Martin, E., Myers, K., \& Brickman, K. (2020). Self-preservation in the workplace: The importance of well-being for social work practitioners and field supervisors. Social Work, 65(1), 74-81. https:// doi.org/10.1093/sw/swz040.

Matta, C. (2012). The stress response: How dialectical behavior therapy can free you from needless anxiety, worry, anger, and other symptoms of stress. Oakland, CA: New Harbinger Publications.

Mervosh, S., Lu, D., \& Swales, V. (2020). See which states and cities have told residents to stay at home. The New York Times, https:// www.nytimes.com/interactive/2020/us/coronavirus-stay-at-homeorder.html.

Miller, J., Lianekhammy, J., \& Grise-Owens, E. (2018). Examining self-care among individuals employed in social work capacities: Implications for the Profession. Advances in Social Work, 18(4), 1250-1266. https://doi.org/10.18060/22320.

Minois, N. (2000). Longevity and aging: Beneficial effects of exposure to mild stress. Biogerontology, 1(1), 15-29. https://doi. org/10.1023/a:1010085823990.

Murray, D., Rosanbalm, K., Christopoulos, C., \& Hamoudi, A. (2015). Self-regulation and toxic stress: Foundations for understanding self-regulation from an applied developmental perspective. $O P R E$ Report \#2015-21, Washington, DC: Office of Planning, Research and Evaluation, Administration for Children and Families, U.S. Department of Health and Human Services.

National Association of Social Workers. (2018). NASW code of ethics. Washington, DC: Author.

Neria, Y., DiGrande, L., \& Adams, B. (2011). Post-traumatic stress disorder following the September 11, 2001, terrorist attacks: A review of the literature among highly exposed populations. The American Psychologist, 66(6), 429-446. https://doi.org/10.1037/ a0024791.

Newell, J., \& Nelson-Gardell, D. (2014). A competency-based approach to teaching professional self-care: An ethical consideration for social work educators. Journal of Social Work Education, 50(3), 427-439. https://doi.org/10.1080/10437797.2014.917928.

Oosterhoff, B., Palmer, C., Wilson, J., \& Shook, N. (2020). Adolescents' motivations to engage in social distancing during the COVID-19 pandemic: Associations with mental and social health. Journal of Adolescent Health. https://doi.org/10.1016/j.jadohealth .2020.05.004.

Owens-King, A. (2019). Secondary traumatic stress and self-care inextricably linked. Journal of Human Behavior in the Social Environment, 29(1), 37-47. https://doi.org/10.1080/10911359.2018.14727 03.

Pew Research Center. (2020). Most Americans say Coronavirus outbreak has impacted their lives. Social \& Demographic Trends. https://www.pewsocialtrends.org/2020/03/30/most-americanssay-coronavirus-outbreak-has-impacted-their-lives/

Polizzi, C., Lynn, S., \& Perry, A. (2020). Stress and coping in the time of COVID-19: Pathways to resilience and recovery. Clinical Neuropsychiatry: Journal of Treatment Evaluation, 17(2), 59-62. https://doi.org/10.36131/CN20200204.

Quintana, C. (2020). College closings: More than 100 colleges cancel in-person classes and move online. USA Today. https://www.usato day.com/story/news/education/2020/03/11/coronavirus-collegeclosings-list-online-classes/5022256002/.

Reeck, C., Ames, D., \& Ochsner, K. (2016). The social regulation of emotion: An integrative, cross-disciplinary model. Trends 
in Cognitive Sciences, 20(1), 47-63. https://doi.org/10.1016/j. tics.2015.09.003.

Rohleder, N. (2019). Stress and inflammation-The need to address the gap in the transition between acute and chronic stress effects. Psychoneuroendocrinology, 105, 164-171. https://doi.org/10.1016/j. psyneuen.2019.02.021.

Roming, S., \& Howard, K. (2019). Coping with stress in college: An examination of spirituality, social support, and quality of life. Mental Health, Religion \& Culture, 22(8), 832-843. https://doi. org/10.1080/13674676.2019.1674794.

Schneiderman, N., Ironson, G., \& Siegel, S. (2005). Stress and health: Psychological, behavioral, and biological determinants. Annual Review of Clinical Psychology, 1, 607-628. https://doi. org/10.1146/annurev.clinpsy.1.102803.144141.

Seery, M., Holman, E., \& Silver, R. (2010). Whatever does not kill us: Cumulative lifetime adversity, vulnerability, and resilience. Journal of Personality and Social Psychology, 99(6), 1025-1041. https://doi.org/10.1037/a0021344.

Shi, W. (2019). Health information seeking versus avoiding: How do college students respond to stress-related information? American Journal of Health Behavior, 43(2), 437-448. https://doi. org/10.5993/AJHB.43.2.18.

Siebert, D. (2006). Personal and occupational factors in burnout among practicing social workers. Journal of Social Service Research, 32(2), 25-44. https://doi.org/10.1300/J079v32n02_02.

Smalley, A. (2020). Higher education responses to coronavirus (COVID-19). National Conference of State Legislatures. https:// www.ncsl.org/research/education/higher-education-responses-tocoronavirus-covid-19.aspx.

Strait, J., Strait, G., McClain, M., Casillas, L., Streich, K., Harper, K., \& Gomez, J. (2020). Classroom mindfulness education effects on meditation frequency, stress, and self-regulation. Teaching of
Psychology, 47(2), 162-168. https://doi.org/10.1177/0098628320 901386.

Taylor, W., Snyder, L., \& Lin, L. (2020). What free time? A daily study of work recovery and well-being among working students. Journal of Occupational Health Psychology, 25(2), 113-125. https:// doi.org/10.1037/ocp0000160.

Ullah, R., \& Amin, S. (2020). The psychological impact of COVID19 on medical students. Psychiatry Research, 288, 1. https://doi. org/10.1016/j.psychres.2020.113020.

Wang, C., Cunningham-Erdogdu, P., Steers, M., Weinstein, A., \& Neighbors, C. (2020). Stressful life events and gambling: The roles of coping and impulsivity among college students. Addictive Behaviors. https://doi.org/10.1016/j.addbeh.2020.106386.

Wilson, F. (2016). Identifying, preventing, and addressing job burnout and vicarious burnout for social work professionals. Journal of Evidence-Informed Social Work, 13(5), 479-483. https://doi. org/10.1080/23761407.2016.1166856.

Publisher's Note Springer Nature remains neutral with regard to jurisdictional claims in published maps and institutional affiliations.

Dawn Apgar is the BSW Program Director and Assistant Chairperson of the Department of Sociology, Anthropology, Social Work, and Criminal Justice.

Thomas Cadmus received his undergraduate social work degree from Seton Hall University in 2020 and is currently pursuing his Master of Social Work (MSW) degree. 